\title{
Autonomous multi-function floor cleaning robot with zig zag algorithm
}

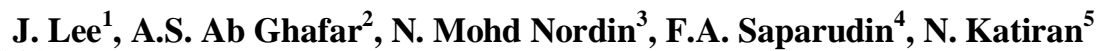 \\ $1,2,3,4,5$ Department of Electrical Engineering Technology, Faculty of Engineering Technology, \\ Universiti Tun Hussein Onn Malaysia, Malaysia \\ 2,3,4,5 Advanced Technology Centre (ATC), Faculty of Engineering Technology, \\ Universiti Tun Hussein Onn Malaysia, Malaysia
}

\begin{tabular}{l}
\hline \hline Article Info \\
\hline Article history: \\
Received Nov 20, 2018 \\
Revised Jan 27, 2018 \\
Accepted Feb 11, 2019 \\
\hline
\end{tabular}

Keywords:

Autonomous

IR sensor

Ultrasonic sensor

Vacuum robot

Water spray

\begin{abstract}
In this present era, people live a very busy life. People in cities have irregular and long working times. In such a situation a person will always find ways of saving time. Household chores are the ones that are most dreaded upon and cleaning a home tops the list. An autonomous floor cleaning robot is developed to help people to complete their cleaning task. This paper presents the development of an autonomous floor cleaning robot by using Arduino as a platform for processing and controlling the input and output. Autonomous vacuum cleaner robot is designed to make cleaning process become easier compared to using manual vacuum. The idea is basically by having the sensor to detect any object and send the input to Arduino that will control the robot movement. This robot can perform vacuum and wiping task with water spray function. It is also programmed to move in zigzag movement to ensure that the robot can clean all the corner of the house and avoid obstacle autonomously. This robot consists of three ultrasonic sensors, one infra-red (IR) sensor and two brushes in front of it to ensure effective cleaning. It is designed to run on flat surface. This autonomous multi-function floor cleaning robot has lower cost compared to existing vacuum robot on the shelves and is suitable for home and small premise usage.
\end{abstract}

Copyright $\odot 2019$ Institute of Advanced Engineering and Science. All rights reserved.

\section{Corresponding Author:}

Aimi Syamimi Ab Ghafar,

Department of Electrical Engineering Technology,

Faculty of Engineering Technology,

Universiti Tun Hussein Onn Malaysia,

Pagoh, Johor, Malaysia.

Email: aimi@uthm.edu.my

\section{INTRODUCTION}

Nowadays, robot is commonly used to accomplish human requirements in daily life $[1,2]$. Authors in [3] discussed the massive introduction of robots and the transition of the economic system to robonomics (robot-based economy) that might affect job opportunities especially where robots are replacing human tasks. Despite this concern, industrial robots have been used for several decades now in warehouse [4, 5], logistics [6, 7], agriculture [8-10], education [11-14], financial trade [15, 16], medicine [17-20], transportation [21-23], tourism and hospitality [24, 25], and others. Recently, robots are also developed as home appliances as the individuals' requests expands [26]. Home mechanical machine technology exploration is getting to be dynamic like never before $[27,28]$. Cleaning robot applications are imminent today and tend to become a mass market. Smart floor cleaner is a mobile robot with cleaning function. It is an intelligent automated cleaner that has perceptive programming and a limit cleaning framework. It designed to make cleaning process easier and save manpower. Most people are working long hours and do not have enough time to clean. Thus, in some of the hospital or old folk's house, the cleaning robot can be used widely 
as it can help the people with physical disabilities and inconvenient elderly people to clean the floor and wipe the floor to prevent falling accident. Hence, these situation leads to the demand of autonomous-type cleaning machine in the market.

The vacuum cleaner robot should have a mechanism such as the artificial intelligence to solve the problem of cleaning the entire environment areas taking into account some factors such as obstacle avoidance and the number of turns it needs to take. Over time, many researchers have come out with different techniques to ensure optimal coverage of the vacuum robot. Authors in [29] used Genetic Algorithms (GA) which, consist of several steps to get the solutions. Each gene represents the robot position and some of chromosomes represent the mini-path the robot is taking. In [30], artificial intelligence is adopted to enable intelligent scheduling and motion control for optimized operation of the vacuum robot. In addition, other movement techniques include spiral, zig zag and cell by cell [31].

The most popular robot movement are zigzag and spiral technique. Movement using zig zag technique is depicted in Figure 1. The zigzag coverage technique only require short range sensors but spiral technique need long range sensors to complete the work. In addition, the shorter the distance of the sensors from the wall when robot takes measurements, the more likely that the measured data is accurate. Moreover, the zigzag technique achieves complete coverage at a faster rate and achieved in the least amount of cleaning time. Application-wise, the zigzag technique is more useful as these algorithms are simple and can be implemented not only in vacuum cleaners but also lawn mowers. The zigzag technique is useful in a household situation for cleaning, as this allows the user to start the robot without the need to move entirely out of the area.

\section{FLOOR CLEANING ROBOT DESIGN}

To develop a project, methodology is the most important part in a project. There are two major elements discussed here which are hardware and software designing.

\subsection{Hardware Development}

The hardware development for the autonomous floor cleaner robot in this project has four phases. First phase is the design and development of the sensors. Ultrasonic sensor is used to detect any blocking objects or obstacles and infrared sensor is used to sense the distance between the mobile robot and the floor. Figure 2 shows the circuit diagram between Arduino Uno and sensor. Second phase is the design and development of vacuum unit. Vacuum unit used DC motor due to the continuous rotation of the motor. The DC motor will be connected to a fan to produce a function of vacuum. Figure 3 shows the circuit diagram of Arduino Uno and DC motor.

Third phase is the design and development of wiping unit with water spray. There is a microfiber cloth underneath the robot and the water will spray a little amount of water for wiping function. Fourth phase is the design and development of the robot movement. $360^{\circ}$ servo motors are used to act as the wheels of the robot due to its continuous rotation with a high torque. Servo motor can be programmed by Arduino Uno for turn clockwise or counter clockwise. The movement of robot setting as zigzag algorithm is to produce a high efficiency on cleaning all the corners of the house. Figure 4 shows the circuit diagram of Arduino Uno and servo motor used for water spray and robot movement.

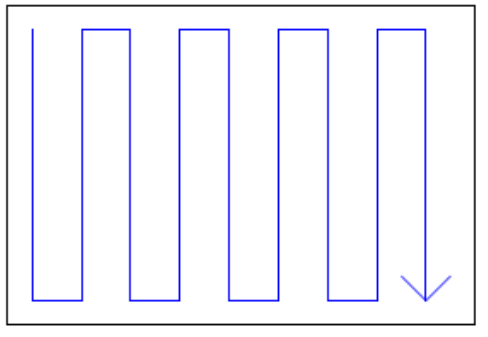

Figure 1. Zigzag motions

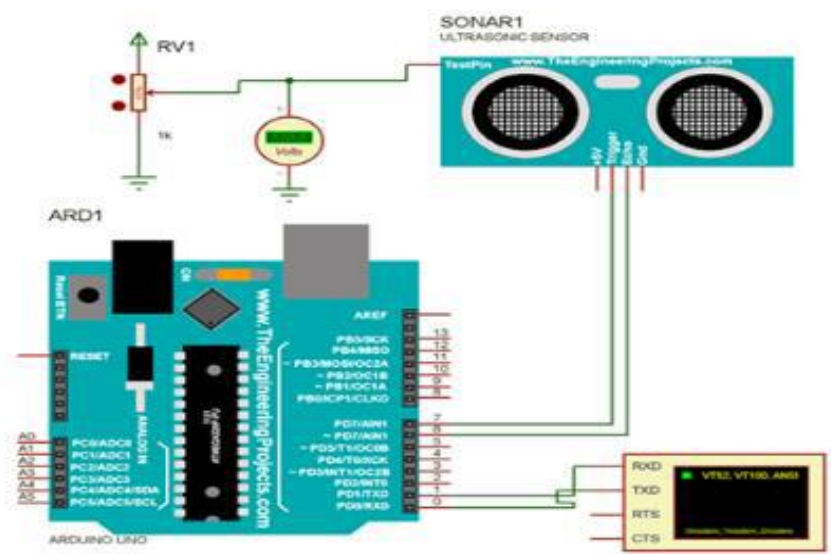

Figure 2. Ultrasonic sensor connection 


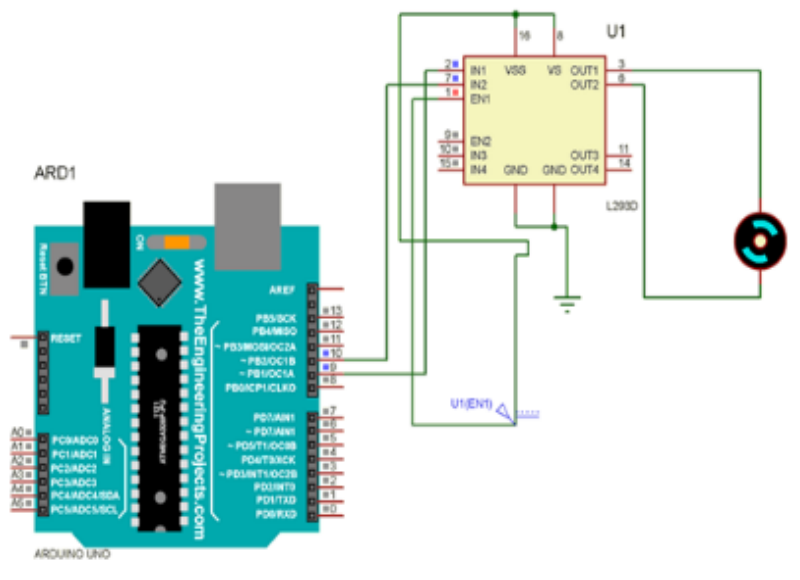

Figure 3. DC motor connection

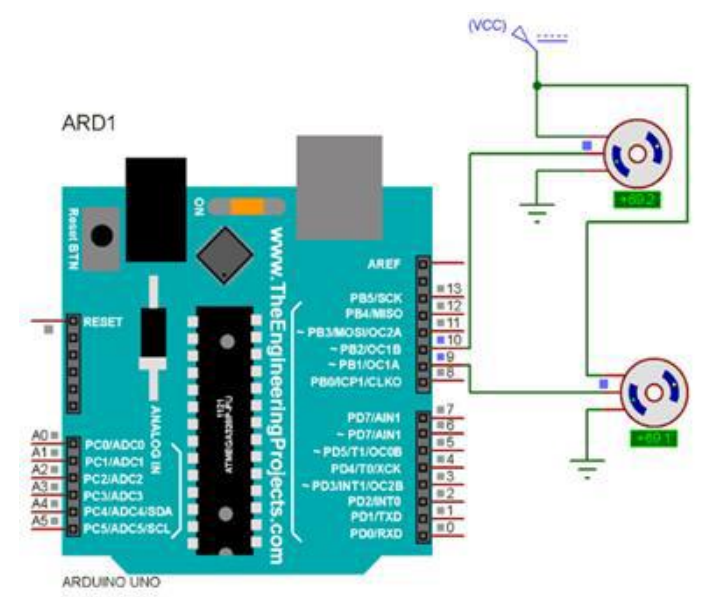

Figure 4. Servo motor connection

\subsection{Software Development}

Figure 5, 6, 7, and 8 show the autonomous floor cleaner robot process from the start till the end, based on the Zig Zag algorithm. This is an autonomous floor cleaner robot which will operate the cleaning process automatically that have been programmed. The whole process is a looping process where it will only stop when the battery is finish. The flowchart covers the whole process of movement for autonomous floor cleaner robot.

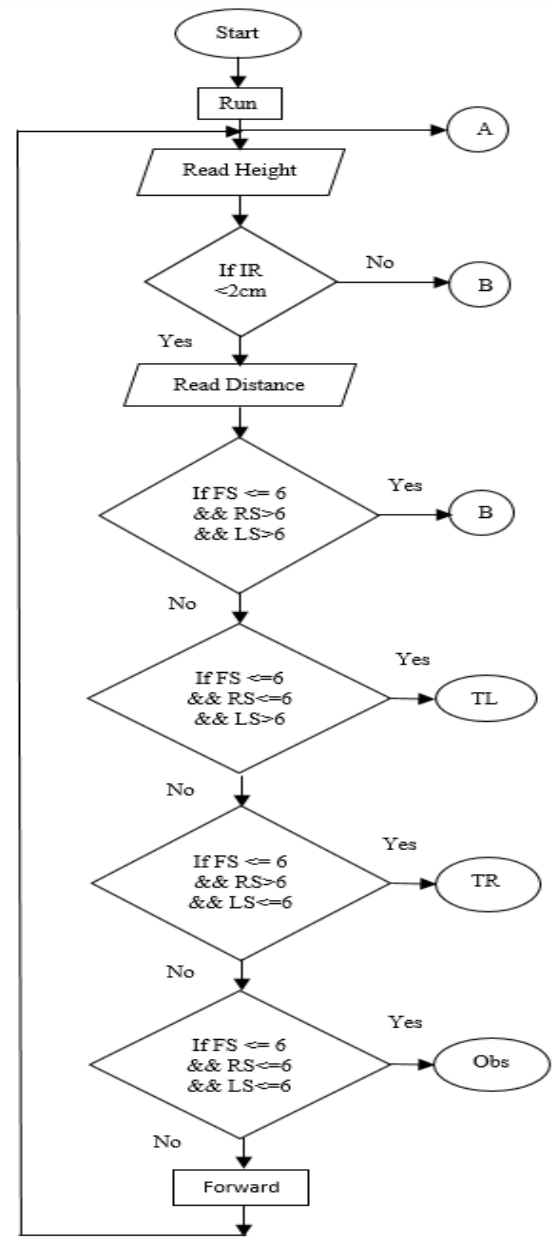

Figure 5. Zig zag movement algorithm

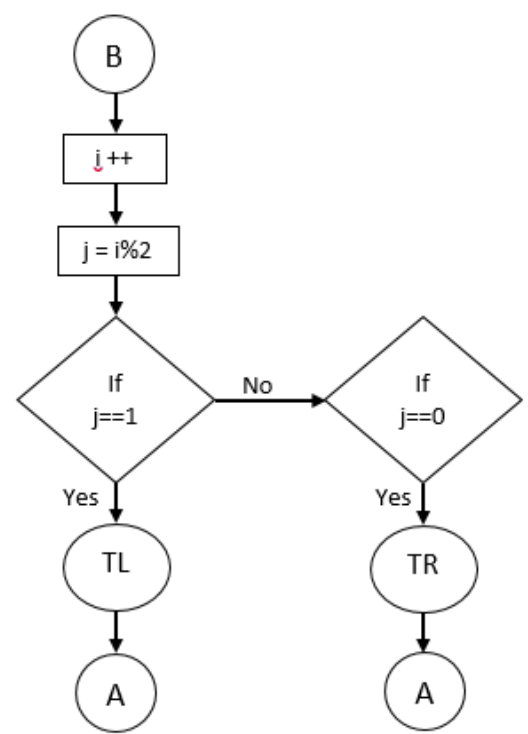

Figure 6. Turning decision 


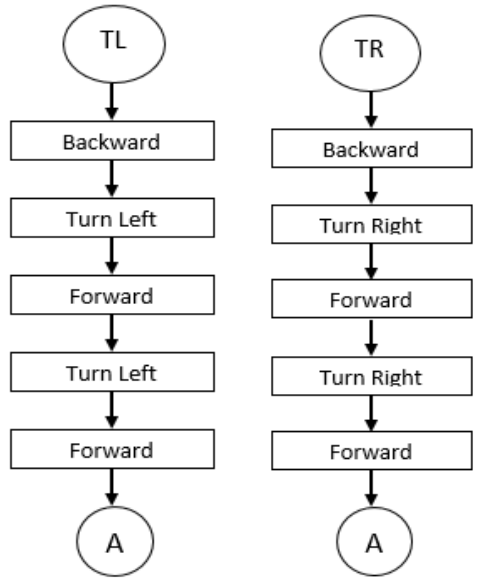

Figure 7. Turning left/right

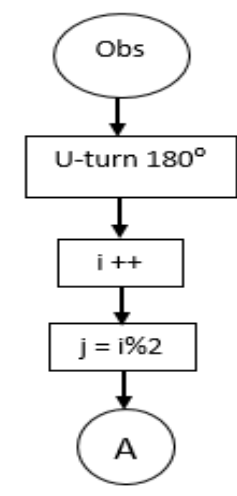

Figure 8. U-turn to avoid obstacle

\subsection{Robot Chassis Development}

The design of the autonomous floor cleaner robot chassis has been constructed using the SketchUp software. The main structure of the robot is shown in Figure 9. The SketchUp software can give view from different sides. There are three ultrasonic sensors installed on both sides and in front of the robot. The function of these ultrasonic sensors are to detect the obstacles or the wall and avoid from collision. When right ultrasonic sensor sense the obstacle, the robot will stop and turn left while when left ultrasonic sensor sense the obstacle, the robot will stop and turn to right. When front ultrasonic sensor sense obstacle, the robot will move backward and will reconsider the direction of movement. From the figure above infrared sensor is installed in front and underneath the robot. The function of infrared sensor is to detect the distance of obstacle on the floor. If the infrared sensor sense the distance between the robot and the floor is more than $2 \mathrm{~cm}$, the robot will move backward to prevent from falling.

\subsection{Overall Design and Setup}

To develop this project, the pathway of the autonomous floor cleaner robot is as shown in Figure 10. The robot consists of two types of sensor to detect and sense object or obstacle. Once the sensor detected object, it will give signal to the robot to change it direction and pathway. The robot will follow zigzag algorithm that is programmed.

In this project, ultrasonic sensors are used as the object detection which can allow the robot to avoid collision. While, infrared sensor is developed as the falling prevention which protect the robot falling from height and destroy. The second step to develop the robot vacuum which sucks the dust and dirt to perform a cleaning process. To increase the efficiency of cleaning process, two additional brush is added on the front side of the robot where it can sweep the dust or dirt into vacuum area and make sure clean every corners of the house.

After that, the third step is to develop the wiping part. The robot can vacuum and wipe the floor at the same time. The water for wiping function is from the water spray which is used to allow the water to flow to the microfiber cloth and then wipe the floor. The amount of water flow out can be adjust by programming the time for motor move. Microfiber cloth is used in this project due to its high ability to absorb the maximum amount of water with minimal losses and volume.

Final step is the development of the robot movement with zigzag algorithm. The zigzag algorithm is selected as it can complete coverage area at a faster rate. The zigzag movement algorithm designed for this robot is according to the inputs from the sensors used.

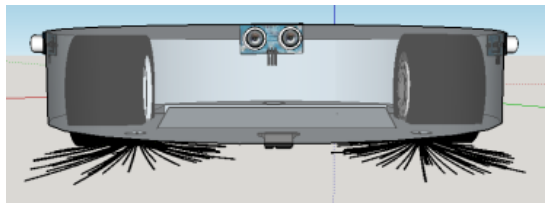

(a) The front view of the robot

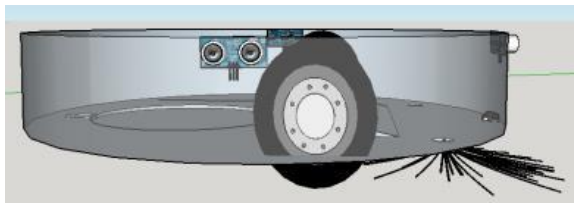

(b) The side view of the robot 


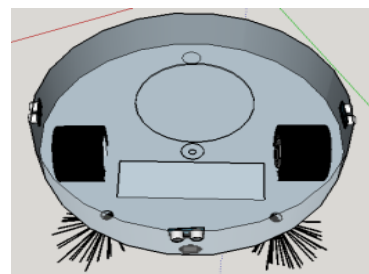

(c) The top view of the robot

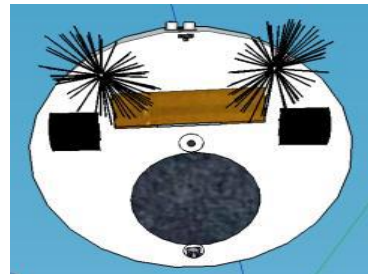

(d) The bottom view of the robot

Figure 9. 3D design of autonomous floor cleaner robot

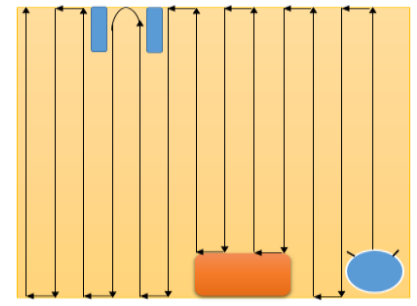

Figure 10. Overall project design

\section{RESULTS AND DISCUSSION}

This section elaborates how the whole system is developed by merging both hardware and software parts. The hardware part is developed and assembled to make sure the connection and components are well functioning. After that, software is developed and programmed into the hardware part to ensure that the robot is in desired condition.

\subsection{Development of Vacuum unit}

The motor that used in the vacuum unit is an $18 \mathrm{~V}$ DC motor which operates at a very high speed with $19500 \mathrm{rpm}$. Water bottle is modified as a dust storage for the vacuum unit. Figure 11(a) shows the space for the bottom motor is very huge due to the theory of vacuum. Figure 11(b) shows the complete development of vacuum unit with DC motor. A filter is placed in front of the fan which is to gather the dust and prevent the dust to damage the motor. The capability of the vacuum only allow dust, hairs and small sand only.

\subsection{Development of Wiping Unit}

The motor that used in the wiping unit in Figure 12(a) is Tamiya's gearbox packs with DC motor which is adjustable to become high torque or low torque. In this project, the motor is adjusted to be high torque for 38rpm because the motor need to rotate the microfiber cloth without stopping. Figure 12(b) shows the water spray bottle. The bottle will be pressed by servo motor and the water will spray out. In this project, the water spray frequency is set at 5 seconds interval. The total number of spray for this water spray bottle can reach up to 240 spray times. The position for the wiping cloth is shown in Figure 12(c) which is underneath the robot.

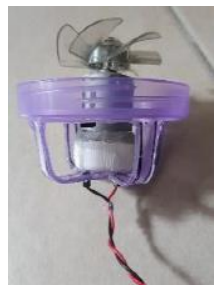

(a) Motor for vacuum unit

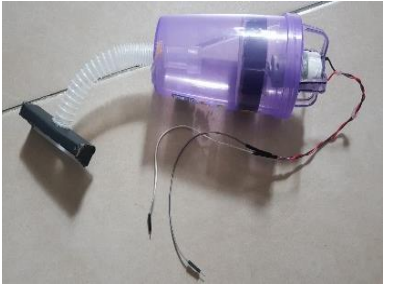

(b) Vacuum unit after assembly

Figure 11. Development of vacuum unit 


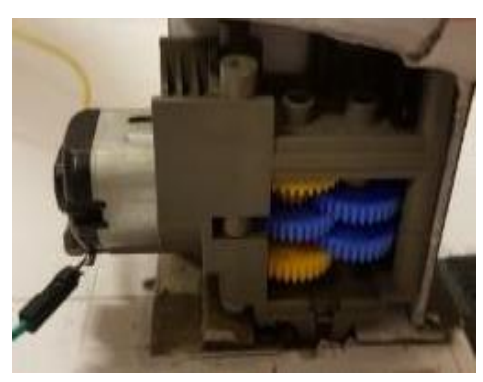

(a) Tamiya's gearbox packs with DC motor

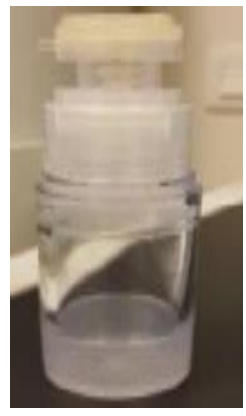

(b) Water spray bottle

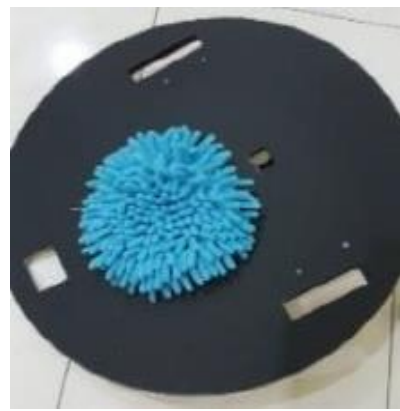

(c) Position of wiping material

Figure 12. Development of wiping unit

\subsection{Development of Robot Movement with Zigzag Algorithm}

The ultrasonic sensors and IR sensor have been arranged on the body of robot for testing the movement of robot. The position of the ultrasonic sensors are the front, the left side and right side of the robot. The purpose for using the ultrasonic sensors is to avoid obstacle and allowing the robot to decide the next movement based on obstacle condition. In the meantime, the position of the IR sensor is underneath of the robot. This is to prevent the robot from falling of the stairs. Figure 13 shows the arrangement of the sensors and the wheel of robot. The robot movement with zigzag algorithm is control by implementing modulo method in programming.

Figure 14(a) shows that the robot continuously moves forward if the IR sensor detect the height between robot and floor is less than $2 \mathrm{~cm}$ and no obstacle. Figure 14(b) shows the front ultrasonic sensor senses the object in less than $5 \mathrm{~cm}$, hence the result shows the output result of $\mathrm{j}$ is equal to one, then it will proceed the turn left. Next, Figure 14(c) shows the front ultrasonic sensor senses the object less than $5 \mathrm{~cm}$ again, the result shows output result of $\mathrm{j}$ is equal to zero, and then it will proceed the turn right. This process will continuous until it meets another condition.

Figure 15(a) shows when the left ultrasonic sensor and front ultrasonic sensor sense obstacles in less than $5 \mathrm{~cm}$, the robot will proceed the turn right function. On the other hand, Figure 15(b) shows when the right ultrasonic sensor and front ultrasonic sensor sense obstacles in less than $5 \mathrm{~cm}$, the robot will carry out the turn left function.

Figure 16(a) shows the result when all three ultrasonic sensors detect the obstacle less than $5 \mathrm{~cm}$, after receive the signal, the robot will make a $180^{\circ} \mathrm{U}$-turn to get out from the space and give a modulo output result. On the other hand, Figure 16(b) and 16(c) show the result of IR sensor when the height detected between robot and floor is more than $2 \mathrm{~cm}$. If the output result is equal to one, the robot will proceed the turn left function while the output result is equal to zero, the robot will proceed the turn left function to avoid from falling.

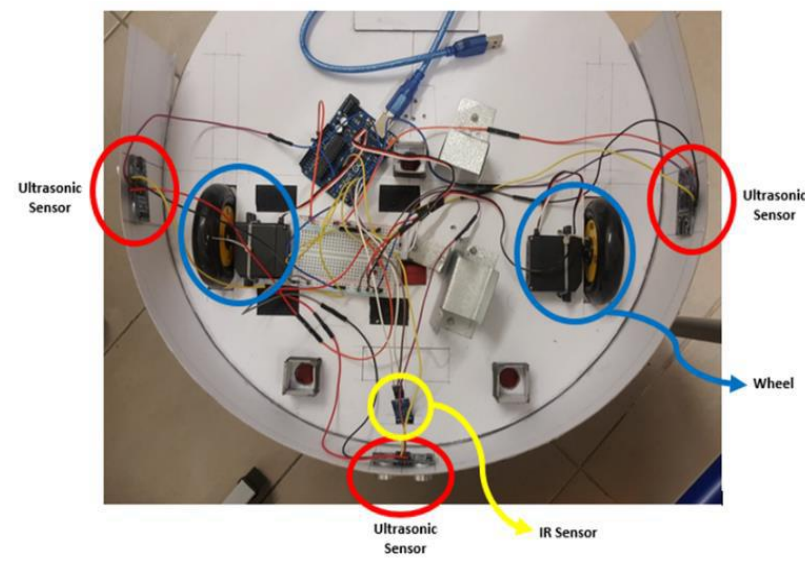

Figure 13. Arrangement of the sensors and the wheel of robot 


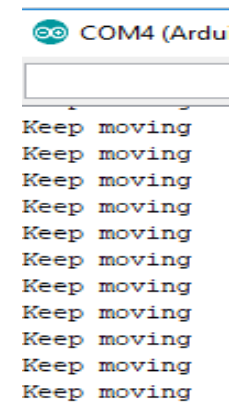

(a) Without obstacle

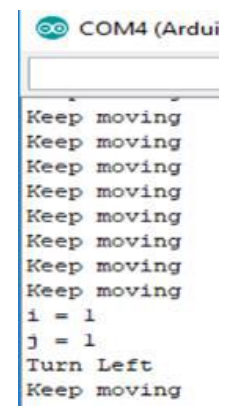

(b) Modulo output $=1$

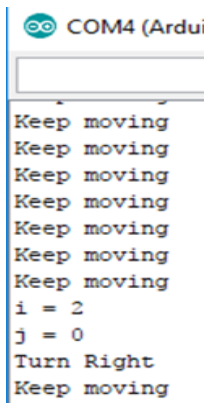

(c) Modulo output $=0$

Figure 14. Front sensor sense and result of modulo output

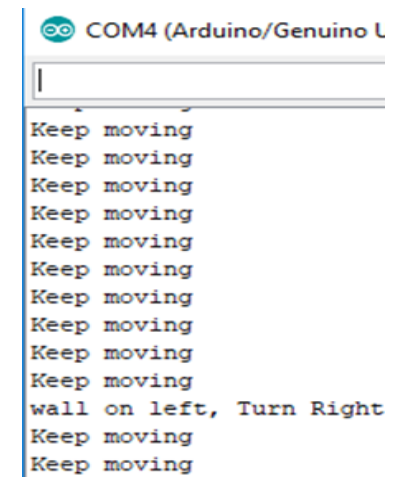

(a) When front and left sensor sense

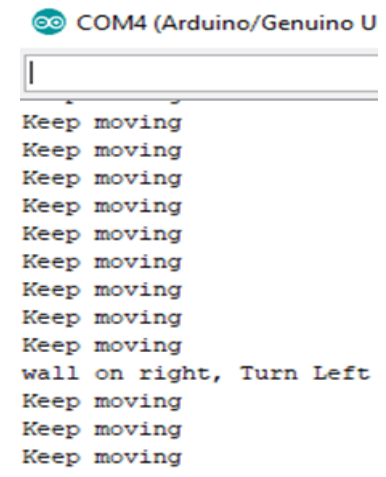

(b) When front and right sensor sense

Figure 15. Front sensor and left or right sensor sense

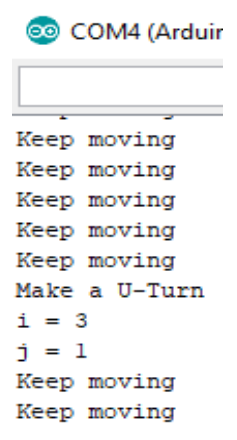

(a) Three sensors sense

\begin{tabular}{l} 
(coM4 (Arduino/Genuino Uno) \\
\hline Keep moving \\
Keep moving \\
Keep moving \\
Keep moving \\
Keep moving \\
Keep moving \\
Keep moving \\
$i=1$ \\
$j=1$ \\
Be careful drop, Turn Left \\
Keep moving
\end{tabular}

(b) IR sensor sense $>2 \mathrm{~cm}$

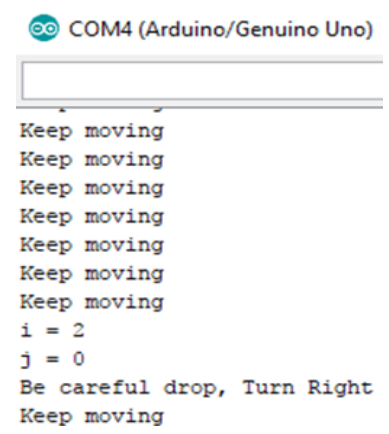

(c) IR sensor sense $>.2 \mathrm{~cm}$

Figure 16. Three sensors sense and result of IR sensor modulo output

\subsection{Battery Performance}

Figure 17(a) shows the Wild Scorpion 3S30C 2200mAh Lithium Polymer (Li-Po) battery that is used in vacuum unit and wiping unit. It is chosen because of its high voltage supply and highly discharge capability. The voltage of this Li-Po battery is $11.1 \mathrm{~V}$, the capacity is $2200 \mathrm{mAh}$, continuous discharge rate is $30 \mathrm{C}$ and it weight $183 \mathrm{~g}$. Figure 18 shows the current measurement from each function unit. The battery usage can be calculated as:

\section{i. Total current of vacuum $=0.1 \mathrm{~A}$}

Battery usage $=\frac{2.2 \mathrm{~A}}{0.1 \mathrm{~A}} \times 60$ mins $=1320 \mathrm{mins}$ 
ii. Total current of wiping unit and two sweep brushes $=1.15 \mathrm{~A}+1.59 \mathrm{~A}=2.74 \mathrm{~A}$

Battery usage $=\frac{2.2 \mathrm{~A}}{2.74 \mathrm{~A}} \times 60$ mins $=48.2 \mathrm{mins}$

Figure 18(b) shows the ZOP Power 7.4V 900mAh 2S 25C Lithium Polymer (Li-Po) battery used in mobility unit to give the power supply for the servo motor due to its high voltage supply. The voltage of this Li-Po battery is $7.4 \mathrm{~V}$, the capacity is $900 \mathrm{mAh}$, continuous discharge rate is $25 \mathrm{C}$ and it weight $45 \mathrm{~g}$. The battery usage can be calculated as:

Total current of servo motor $=0.99 \mathrm{~A}$

Battery usage $=\frac{0.9 \mathrm{~A}}{0.99 \mathrm{~A}} \times 60$ mins $=54.5 \mathrm{mins}$

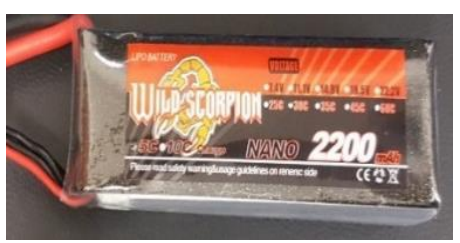

(a) Wild scorpion 3S30C 2200mAh Li-Po battery

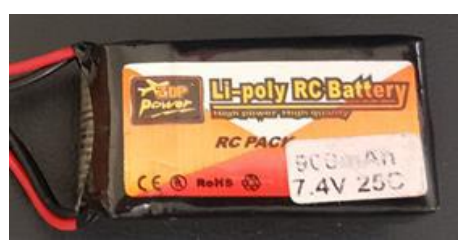

(b) ZOP power $7.4 \mathrm{~V} 900 \mathrm{mAh} 2 \mathrm{~S} 25 \mathrm{C}$ Lithium polymer (Li-Po) battery

Figure 17. Battery used in the project

\subsection{Autonomous Floor Cleaner Robot with Complete Specifications}

Figure 19 shows the complete autonomous floor cleaner robot prototype. After testing the autonomous floor cleaning robot, it can successfully work with desired function and specifications of the robot has been analysed and recorded in the Table 1.

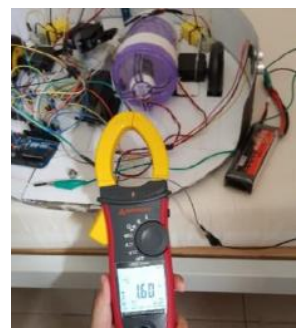

(a) Current of vacuum unit

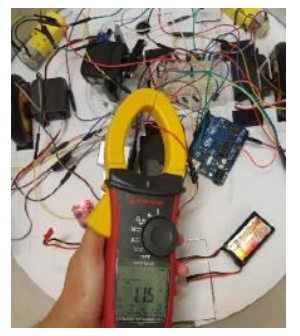

(b) Current of wiping unit

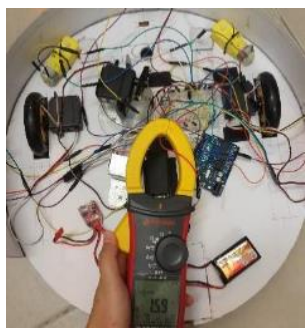

(c) Current of two sweep brushes

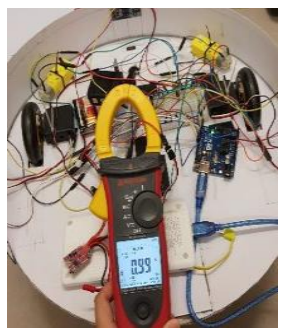

(d) Current of mobility unit

Figure 18. Current value of each unit

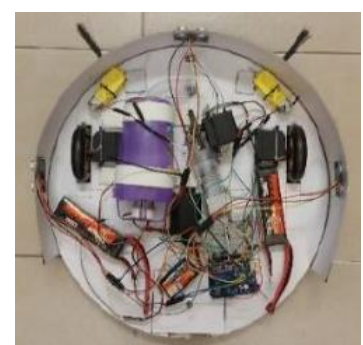

(a) Autonomous floor cleaner robot prototype

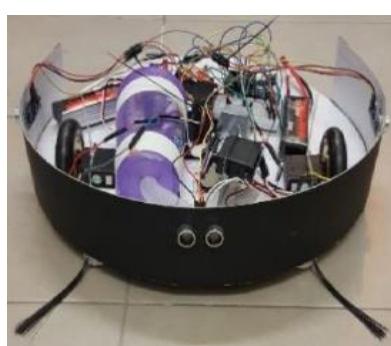

(b) Front view

Figure 19. Complete autonomous floor cleaner robot prototype 
This autonomous floor cleaner robot performs a zigzag movement algorithm when the cleaning time. The Figure 20 shows the testing of the robot movement in a $1.5 \mathrm{~m}^{2}$ area. The time taken for the autonomous floor cleaner robot to complete a $1.5 \mathrm{~m}^{2}$ area is $55 \mathrm{~seconds}$. The speed of the autonomous floor cleaner robot is $0.21 \mathrm{~m} / \mathrm{s}$. The vacuum capability of autonomous floor cleaner robot only allow dust, hair and small sand due to the small size of the dust storage and the performance of the vacuum motor. Moreover, the run time of the autonomous floor cleaner is 48 minutes taken from the shortest time of battery usage which is calculated in Section 3, 4. Therefore, this robot can spend 48 minutes to clean a coverage of 78.54 $\mathrm{m}^{2}$ on a smooth surface in the house. The cleaning coverage of the robot can be calculated by using mathematical method:

Time taken to clean $1 \mathrm{~m} \times 1.5 \mathrm{~m}$ area $=55 \mathrm{~s}$

Time taken to clean $Z$ area $=48 \times 60 \mathrm{~s}=2880 \mathrm{~s}$

$$
\begin{aligned}
\frac{2880 s}{55 s} & =\frac{Z}{1.5} m^{2} \\
Z & =78.54 m^{2}
\end{aligned}
$$

Therefore, $Z$ is the area that can be clean with a time taken of 48 minutes.

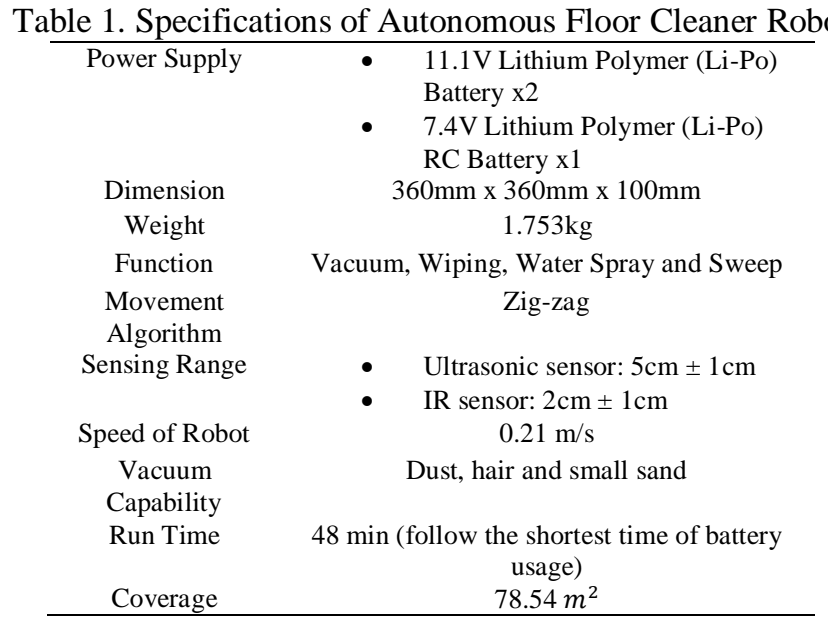

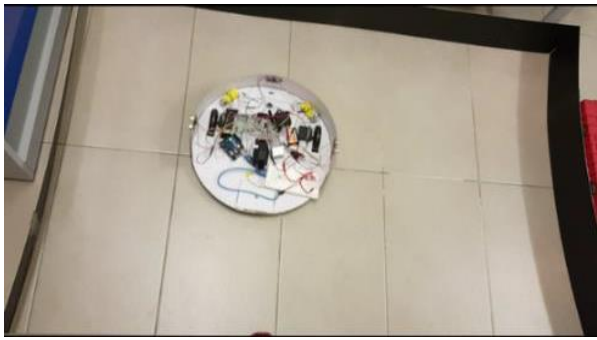

Figure 20. Testing of the robot movement in a $1.5 m^{2}$ area

\section{CONCLUSION}

In conclusion, the objectives of this project have been achieved. Based on the results presented, an autonomous floor cleaner robot prototype has been successfully developed. The autonomous floor cleaner robot prototype has successfully managed its movement by following the zigzag technique. The sensors used in the robot provides input to the programmed robot to move automatically. Moreover, the autonomous floor cleaner robot prototype has managed to clean all the corners of the floor successfully with a systematic control system. The speed of the autonomous floor cleaner robot is $0.21 \mathrm{~m} / \mathrm{s}$. The time taken for the robot to clean a specific area $1.5 \mathrm{~m}^{2}$ is $55 \mathrm{~seconds}$. The run time of the autonomous floor cleaner is 48 minutes taken from the shortest time of battery usage which is calculated in Section 4 . Therefore, this robot can spend 48 minutes to clean a coverage of $78.54 \mathrm{~m}^{2}$ on a smooth surface in the house. The autonomous floor cleaner robot prototype can only function on flat surface and is capable to vacuum dust, hairs and small sands. Lastly, the autonomous floor cleaner robot prototype is successfully designed to have dust vacuum, water spraying and wiping capability. The autonomous floor cleaner robot is designed and developed under the scope of project which fulfilled the objectives. In short, this project can help to solve the hygiene problem in the house and facilitate human task.

\section{ACKNOWLEDGEMENTS}

This work was supported by Ministry of Higher Education (MOHE), Faculty of Engineering Technology, Research Management Centre, Universiti Tun Hussein Onn Malaysia (UTHM) under Fundamental Research Grant Scheme (FRGS) (Vote No: 1619) and Short Term Grant (STG) (Vote No. U524). 


\section{REFERENCES}

[1] D. Acemoglu and P. Restrepo, "Robots and jobs: Evidence from US labor markets," 2017.

[2] G. Graetz and G. Michaels, "Robots at work," Rev. Econ. Stat., vol. 100, no. 5, pp. 753-768, 2018.

[3] S. H. Ivanov, "Robonomics-principles, benefits, challenges, solutions," 2017.

[4] W. Xiao-Long, W. Chun-Fu, L. Guo-Dong, and C. Qing-Xie, "A robot navigation method based on rfid and qr code in the warehouse," in 2017 Chinese Automation Congress (CAC), 2017, pp. 7837-7840.

[5] M. Schwarz, A. Milan, C. Lenz, A. Munoz, A. S. Periyasamy, M. Schreiber, S. Schüller, and S. Behnke, "NimbRo Picking: Versatile part handling for warehouse automation," in 2017 IEEE International Conference on Robotics and Automation (ICRA), 2017, pp. 3032-3039.

[6] A. Farinelli, E. Zanotto, E. Pagello, and others, "Advanced approaches for multi-robot coordination in logistic scenarios," Rob. Auton. Syst., vol. 90, pp. 34-44, 2017.

[7] B. Bona, L. Carlone, M. Indri, and S. Rosa, "Supervision and monitoring of logistic spaces by a cooperative robot team: methodologies, problems, and solutions," Intell. Serv. Robot., vol. 7, no. 4, pp. 185-202, 2014.

[8] A. English, P. Ross, D. Ball, and P. Corke, "Vision based guidance for robot navigation in agriculture," in 2014 IEEE International Conference on Robotics and Automation (ICRA), 2014, pp. 1693-1698.

[9] B. S. Shivaprasad, M. N. Ravishankara, and B. N. Shoba, "Design and implementation of seeding and fertilizing agriculture robot," Int. J. Appl. or Innov. Eng. Manag., vol. 3, no. 6, pp. 251-255, 2014.

[10] R. Bogue, "Robots poised to revolutionise agriculture," Ind. Robot An Int. J., vol. 43, no. 5, pp. 450-456, 2016.

[11] L. N. Brown and A. M. Howard, "The positive effects of verbal encouragement in mathematics education using a social robot," in 2014 IEEE Integrated STEM Education Conference, 2014, pp. 1-5.

[12] M. Fridin, "Storytelling by a kindergarten social assistive robot: A tool for constructive learning in preschool education," Comput. Educ., vol. 70, pp. 53-64, 2014.

[13] J. E. Aoun, Robot-proof: higher education in the age of artificial intelligence. MIT Press, 2017.

[14] K.-Y. Chin, Z.-W. Hong, and Y.-L. Chen, "Impact of using an educational robot-based learning system on students' motivation in elementary education," IEEE Trans. Learn. Technol., vol. 7, no. 4, pp. 333-345, 2014.

[15] V. Dhar, "Should You Trust Your Money to a Robot?" Mary Ann Liebert, Inc. 140 Huguenot Street, 3rd Floor New Rochelle, NY 10801 USA, 2015.

[16] M. Salo and H. Haapio, "Robo-Advisors and investors: Enhancing human-robot interaction through information design," 2017.

[17] B. H. Bochner, D. D. Sjoberg, and V. P. Laudone, "A randomized trial of robot-assisted laparoscopic radical cystectomy," N. Engl. J. Med., vol. 371, no. 4, pp. 389-390, 2014.

[18] G. H. KleinJan, N. S. van den Berg, J. de Jong, E. M. Wit, H. Thygessen, E. Vegt, H. G. van der Poel, and F. W. B. van Leeuwen, "Multimodal hybrid imaging agents for sentinel node mapping as a means to (re) connect nuclear medicine to advances made in robot-assisted surgery," Eur. J. Nucl. Med. Mol. Imaging, vol. 43, no. 7, pp. 1278-1287, 2016.

[19] C.-H. Kim, H. K. Byeon, Y. S. Shin, Y. W. Koh, and E. C. Choi, "Robot-assisted Sistrunk operation via a retroauricular approach for thyroglossal duct cyst," Head Neck, vol. 36, no. 3, pp. 456-458, 2014.

[20] P. P. Dangle, A. Shah, and M. S. Gundeti, "Robot-assisted laparoscopic ureteric reimplantation: extravesical technique," BJU Int., vol. 114, no. 4, pp. 630-632, 2014.

[21] L. Rozo, S. Calinon, and D. G. Caldwell, "Learning force and position constraints in human-robot cooperative transportation," in The 23rd IEEE International Symposium on Robot and Human Interactive Communication, 2014, pp. 619-624.

[22] N. Hirose, R. Tajima, and K. Sukigara, "Personal robot assisting transportation to support active human lifeHuman-following method based on model predictive control for adjacency without collision," in 2015 IEEE International Conference on Mechatronics (ICM), 2015, pp. 76-81.

[23] C. Masone, H. H. Bülthoff, and P. Stegagno, "Cooperative transportation of a payload using quadrotors: A reconfigurable cable-driven parallel robot," in 2016 IEEE/RSJ International Conference on Intelligent Robots and Systems (IROS), 2016, pp. 1623-1630.

[24] S. H. Ivanov and C. Webster, "Adoption of robots, artificial intelligence and service automation by travel, tourism and hospitality companies--a cost-benefit analysis," Artif. Intell. Serv. Autom. by Travel. Tour. Hosp. Companies--A Cost-Benefit Anal., 2017.

[25] P. Alexis, "R-Tourism: Introducing the Potential Impact of Robotics and Service Automation in Tourism.," Ovidius Univ. Ann. Ser. Econ. Sci., vol. 17, no. 1, 2017.

[26] A. Sharkey, "Robots and human dignity: a consideration of the effects of robot care on the dignity of older people," Ethics Inf. Technol., vol. 16, no. 1, pp. 63-75, 2014.

[27] S. Pfeiffer, "Robots, Industry 4.0 and humans, or why assembly work is more than routine work," Societies, vol. 6, no. 2 , p. 16, 2016.

[28] A. Moniz and B.-J. Krings, "Robots working with humans or humans working with robots? Searching for social dimensions in new human-robot interaction in industry," Societies, vol. 6, no. 3, p. 23, 2016.

[29] M. A. Yakoubi and M. T. Laskri, "The path planning of cleaner robot for coverage region using Genetic Algorithms," J. Innov. Digit. Ecosyst., vol. 3, no. 1, pp. 37-43, 2016.

[30] H. Lee and A. Banerjee, "Intelligent scheduling and motion control for household vacuum cleaning robot system using simulation based optimization," in 2015 Winter Simulation Conference (WSC), 2015, pp. 1163-1171.

[31] iRobot Corporation, "Scooba 400 Series Owner's Manual," 2014. 


\section{BIOGRAPHIES OF AUTHORS}
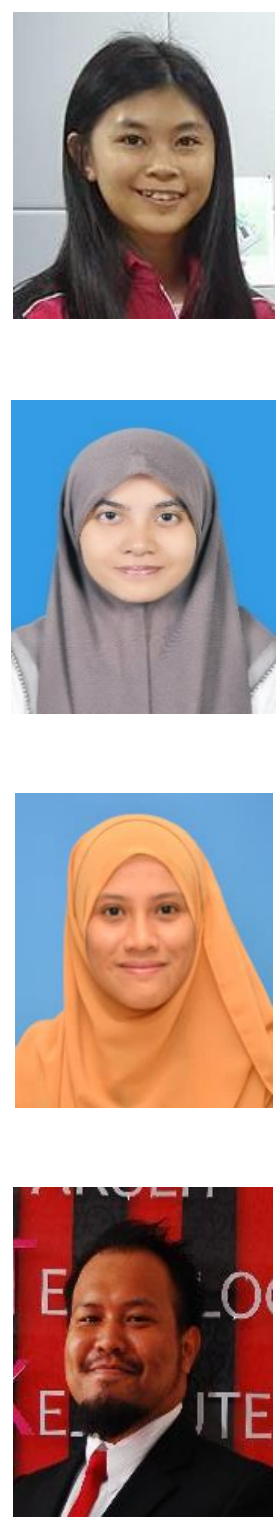

Faiz Asraf Saparudin received his Bachelor B.Sc. in Electrical Engineering (Telecommunication) with First Class Honours from Universiti Teknologi Malaysia in 2010 and received WAMY Academic Excellence Award in the same year. Ph.D. degree in Electrical Engineering (Telecommunication) from the Universiti Teknologi Malaysia in 2015. He is currently a Faculty Member in Fakulti Teknologi Kejuruteraan, Universiti Tun Hussein Onn Malaysia. Member of Institue of Electrical and Electronic Engineers (IEEE) and IEEE Communication Society (ComSoc). His current research interests include radio resource management, distributed algorithms, nature-inspired techniques, multiagent system and game theoretic approach for next-generation mobile network.

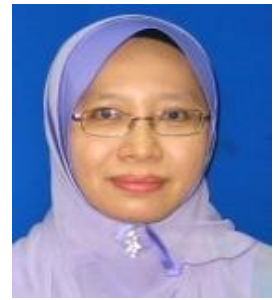

Norshidah Katiran received her Ph.D in Electrical Engineering from Universiti Teknologi Malaysia, in 2015, her M.Eng. degree in Communication and Computer Engineering from Universiti Kebangsaan Malaysia, in 2004, and her B.Eng. degree in Electrical Engineering (Telecommunications) from Universiti Teknologi Malaysia, in 2001. Currently, she is a Senior Lecturer in the Department of Communication Engineering at Universiti Tun Hussein Onn Malaysia. Her major research interests include optimization of resource allocation in cooperative networks and multiple input multiple output (MIMO) transmissions. 